\title{
Influence of secretory phenotype and preoperative preparation on surgical outcome in pheochromocytoma
}

\author{
Raluca Maria Furnica ${ }^{1, *}$, Muhammad Muddaththir Dusoruth ${ }^{1, *}$, Alexandre Persu ${ }^{2}$, Damien Gruson ${ }^{3}$, \\ Michel Mourad ${ }^{4}$ and Dominique Maiter ${ }^{1}$ \\ 'Department of Endocrinology and Nutrition, Cliniques Universitaires Saint-Luc, Université Catholique de Louvain, Brussels, Belgium \\ ${ }^{2}$ Department of Cardiology, Cliniques Universitaires Saint-Luc, Université Catholique de Louvain, Brussels, Belgium \\ ${ }^{3}$ Department of Biology, Cliniques Universitaires Saint-Luc, Université Catholique de Louvain, Brussels, Belgium \\ ${ }^{4}$ Endocrine Surgery, Cliniques Universitaires Saint-Luc, Université Catholique de Louvain, Brussels, Belgium \\ Correspondence should be addressed to D Maiter: dominique.maiter@uclouvain.be \\ *(R M Furnica and M M Dusoruth contributed equally to this work)
}

\begin{abstract}
Objectives: Surgery of pheochromocytomas (PCs) still carries a high risk of haemodynamic complications during the perioperative period. We aimed to evaluate the influence of their secretory phenotype and preoperative alpha-blocker treatment on surgical outcome.

Design: A retrospective monocentric study at a tertiary medical centre.

Patients: In this study, 80 consecutive patients operated by the same team for a PC between 1988 and 2018.

Results: Diagnosis was based on typical symptoms and signs in 58 patients, genetic testing in 12 and work-up of an adrenal incidentaloma in 9. It was made during surgery in one patient. A genetic predisposition was found in one-third of index cases (21/62). The majority of the patients (73/79) had a secreting PC; more than $2 / 3$ had an adrenergic phenotype and less than $1 / 3$ a noradrenergic phenotype. The rate of perioperative haemodynamic complications was not influenced by the secretory phenotype, but persistent hypertension after surgery, recurrence and malignancy were more frequently observed in patients with a noradrenergic tumour. Preoperative alpha-blocker treatment was given for $\geq 14$ days in 29 patients and, although being more symptomatic at diagnosis, these patients had less haemodynamic complications (3/29 vs 12/51 nontreated patients, $P=0.05$ ).

Conclusions: The occurrence of haemodynamic complications during surgery was not significantly affected by the secretory phenotype in our study, but noradrenergic tumours show a worse post-surgical outcome. Our data also provide additional support in favour of a sufficient preoperative alpha-blockade in patients with pheochromocytoma.
\end{abstract}
Key Words
- pheochromocytoma
- alpha-blockers
- complications
- surgery

\section{Introduction}

Clinical presentation of pheochromocytomas and paragangliomas (PPGL) is highly variable, making early diagnosis often challenging. The pattern and haemodynamic effects of tumoural catecholamine secretion may indeed vary from a biochemically and clinically silent chromaffin adrenal tumour to a highly expressive pheochromocytoma inducing severe hypertension with or without superimposed bursts $(1,2,3)$. https://ec.bioscientifica.com

https://doi.org/10.1530/EC-20-0537 (c) 2021 The authors Published by Bioscientifica Ltd
Endocrine Connections (2021) 10, 92-101

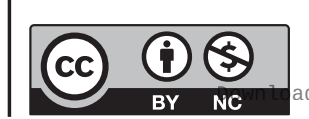

This work is licensed under a Creative Commons Attribution-NonCommercial 4.0 International License. ded from Bioscientifica.com at 04/26/2023 11:28:28AM 
Severe cardiovascular complications may ensue, such as a Takotsubo-like acute myocardial syndrome or chronic hypertrophic or dilated cardiomyopathy (4).

For decades, the diagnosis of PPGL has been most commonly based on the presence of paroxysmal or sustained hypertension, associated with suggestive symptoms and signs such as palpitations, pallor, tremor, hyperhidrosis and nausea (5). Over the last years, however, pheochromocytomas have been increasingly diagnosed during the work-up of an incidentally discovered adrenal mass $(6,7,8)$ or as a result of genetic case detection testing, as these tumours carry a very high rate of germline mutations, up to $35-40 \%$ in recent series $(9,10,11)$

Surgery represents the primary treatment of PPGL $(2,3)$. Thanks to improvements in medical treatment, anaesthesia and surgical techniques, the mortality has dropped markedly to an acceptable range of $0-3 \%$, but the risk of cardiovascular complications during the perioperative period remains high $(12,13)$. Preoperative medical treatment with alpha-blockers is currently recommended, at least in hormonally functional PPGL, as it might improve surgical outcome $(2,14)$. However, controversy persists regarding the true clinical benefits of such preparation, partly due to the lack of a well-designed placebo-controlled trial (14) and the optimal preparation has not been yet clearly defined $(12,15)$. For instance, some authors have proposed that only patients with severe and complicated hypertension require blood pressure normalisation prior to surgery $(16,17)$.

Both perioperative manifestations and surgical outcome seem to be related to the severity and phenotype of catecholamine secretion. In particular, the amount of preoperative total urinary metanephrine excretion has been reported as an independent risk factor for morbimortality during surgical resection of the tumour (18). In addition, predominant norepinephrine secretion is characterised by a more sustained hypertension and an absence or reversal of nocturnal blood pressure dipping that may lead to a higher prevalence of target organ damage (19).

The aims of our study were to characterise a large series of patients treated in our tertiary centre for an adrenal pheochromocytoma (PC) and to determine whether the secretory phenotype could influence surgical complications and long-term outcome. We also thought to determine whether an adequate preoperative medical preparation with alpha-blockers improved surgical outcome.

\section{Materials and methods}

\section{Patients}

We retrospectively analysed the data from 80 consecutive patients who were managed by the same clinical team and who had undergone adrenal surgery between 1988 and 2018 in our academic centre to remove an immunohistochemically confirmed pheochromocytoma, Twelve patients were operated before 2000 and 68 thereafter, while 4 other patients had to be excluded because of insufficient follow-up data. We collected patient's characteristics, symptoms and complications at diagnosis, hormonal results, non-invasive imaging techniques used to localise PC, tumour size, preoperative medical preparation, type of surgery, complications that occurred during and within $24 \mathrm{~h}$ after surgical intervention, as well as postoperative outcome including evolution of hypertension, PC relapse, malignant transformation and death. The median duration of follow-up was 53 months (P5-P95 interval: 6-248 months).

The circumstances of diagnosis were available in 74 patients only, whereas preoperative urinary catecholamine excretion was available in 79 patients (24-h urine fractionated metanephrines in 74 patients, 24-h urinary epinephrine and norepinephrine in 5 patients diagnosed before 1996, and no data in one patient with a PC diagnosed at the time of surgery). The patients were divided into three subgroups according to the tumour secretory phenotype, as proposed by Eisenhofer et al. (20, 21): (i) adrenergic tumours (PCs secreting metanephrine and/or epinephrine, alone or in combination with normetanephrine/norepinephrine), (ii) noradrenergic tumours (PCs secreting only norepinephrine and normetanaphrine), and (iii) biochemically silent tumours (both urinary metanephrine and normetanephrine concentrations in the normal range). Blood genetic testing was routinely performed in every PPGL patient since 1998 and data were available in 70/80 patients. Only the first family member diagnosed with PC was taken into consideration to calculate the proportion of genetic disease.

We considered that patients had received adequate preoperative medical preparation if they had been treated with an alpha-adrenergic receptor blocker for at least 14 days before surgery. This 2-week-period was selected based on current guidelines (2) and procedures adopted by most other centers (12). Two patients receiving preoperative alpha-blockers for only 4 and 6 days were therefore not included in this subgroup. 
Major hypertensive peaks (systolic blood pressure $\geq 300 \mathrm{mmHg}$, cardiac arrhythmia, acute pulmonary oedema, cardiac arrest and vasoplegic shock during or early after surgery were all considered as severe haemodynamic perioperative complications. We also included as outcome measures a prolonged total surgical stay (>10 days) and a prolonged stay $(>24 \mathrm{~h}$ ) in the intensive care unit (ICU). Indeed, several patients with no perioperative complications were systematically monitored in the ICU during the first postoperative day. Postoperative normalisation of blood pressure was defined as repeated normal ambulatory blood pressures without any anti-hypertensive drug both at home and during outpatient visits for at least 6 months after surgery.

\section{Hormone assays}

Epinephrine, norepinephrine and fractionated metanephrines were measured on 24-h urine collection. Urine samples were collected in polyethylene containers with $15 \mathrm{~mL}$ of $\mathrm{HCl} 6 \mathrm{~N}$ used as a preservative and stored at $4^{\circ} \mathrm{C}$. Assays were always performed within 2 weeks. Until the end of 2018, urinary catecholamines and metanephrines concentrations were determined by HPLC method with electrochemical detection. An internal standard (dehydroxylbenzylamine/DHBA) was included with each extraction to monitor recovery and facilitate quantification. Since 2019, in order to increase throughput, reduce solvent use and enhance resolution, urinary catecholamines and metabolites were measured using ultra-performant liquid chromatography on Acquity® systems with electrochemical detector ECD 2465 (Waters Corporation, Milford, MA, USA).

\section{Statistics}

Statistical analyses were performed using the SPSS Statistics version 25.0 software (SPSS Inc., Chicago, IL, USA). The continuous variables were reported as mean \pm S.D., or as median and (P5-P95) interval. The normality of the data was assumed for a sample size greater than or equal to 30 according to the strong law of large numbers. Continuous variables were compared using Student's unpaired $t$-tests whereas ANOVA was used for multiple comparisons. Discrete variables were compared by the Chi-square test. For multiple comparisons, the significance threshold was adjusted by the Bonferroni method. Correlations were calculated using Pearson's regression analysis. A multivariate logistic regression analysis was also performed to determine factors independently predicting peroperative haemodynamic complications. A $P$ value of less than 0.05 was considered statistically significant. The study was approved by the Ethics Committee of the Cliniques Universitaires Saint Luc of Brussels.

\section{Results}

\section{General characteristics at diagnosis}

The study population included 80 patients (39 men and 41 women, mean age at diagnosis: $47 \pm 18$ years) (Table 1 ). A significant proportion of patients (58/79) had hypertension and more than half had abnormal glucose metabolism, either diabetes $(n=21)$ or impaired fasting glycaemia $(n=22)$. Clinical manifestations at diagnosis were present in 53/74 patients. Thirty-seven subjects had one or more typical manifestations of PC (paroxystic crises of headaches, palpitations, diaphoresis, and/or pallor associated with hypertension), while the other

Table 1 General characteristics of the 80 patients operated for an adrenal pheochromocytoma.

\begin{tabular}{|c|c|}
\hline & All patients $(n=80)$ \\
\hline Mean age at diagnosis (years) & $47.0 \pm 18.4$ \\
\hline Patients aged $<50$ years & $40 / 80$ \\
\hline Sex ratio (men/women) & $39 / 41$ \\
\hline Mean BMI $\left(\mathrm{kg} / \mathrm{m}^{2}\right)$ & $24.8 \pm 5.0$ \\
\hline Mean tumour diameter $(\mathrm{cm})^{a}$ & $5.4 \pm 3.4$ \\
\hline Family history of PC & $17 / 74$ \\
\hline Patients with hypertension & $58 / 79$ \\
\hline Systolic blood pressure at diagnosis (mmHg) & $160 \pm 40$ \\
\hline Diastolic blood pressure at diagnosis (mmHg) & $92 \pm 20$ \\
\hline Patients with abnormal blood glucose level & $43 / 79$ \\
\hline
\end{tabular}

Data are shown as mean \pm S.D., medians and (P5-P95) intervals or proportions.

aMean diameter based on pathology report.

PC, pheochromocytoma.

https://ec.bioscientifica.com

https://doi.org/10.1530/EC-20-0537 (c) 2021 The authors Published by Bioscientifica Ltd

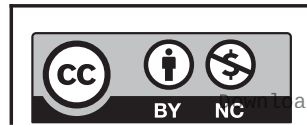

This work is licensed under a Creative Commons Attribution-NonCommercial 4.0 International License. ded from Bioscientifica.com at 04/26/2023 11:28:28AM via free access 
patients presented with Takotsubo-like cardiomyopathy $(n=5)$, abdominal pain $(n=5)$, malignant hypertension $(n=3)$ or other symptoms related to tumour or metastases $(n=3)$. In the 21 asymptomatic patients, diagnosis was made during familial genetic screening in 12 or following incidental discovery of an adrenal mass in nine.

The most effective imaging techniques to localise PC were abdominal CT-scan and MRI, both techniques identifying the adrenal tumour in all cases they were performed (61 and 43 patients, respectively). ${ }^{123}$ I meta-iodo-benzyl-guanidine (MIBG) scintigraphy was performed in 54 patients and correctly identified the tumour(s) in 49 , whereas ${ }^{18} \mathrm{~F}$-deoxyglucose PET fused with CT was also regularly performed during the last ten years and showed hypermetabolism of the tumour in 15/17 cases with a maximum SUV value of $6.1 \pm 3.9$. Six patients had a bilateral PC at diagnosis, whereas two other patients developed a metachronous controlateral PC during follow-up. Two patients had liver metastases at diagnosis.

\section{Genetic testing}

Genetic testing was performed in 70 patients and a germline mutation in one of the known susceptibility genes was found in 29 of them. When only the first family member was considered, one-third of the tested patients $(21 / 62)$ had a hereditary disease. The mutated genes were RET ( $n=9), \operatorname{VHL}(n=5), \operatorname{SDHB}(n=3), \operatorname{SDHD}(n=1), N F 1$ $(n=2)$ and MAX $(n=1)$. Compared to patients with a sporadic pheochromocytoma, index patients harbouring a germline mutation were diagnosed at a younger age ( $40 \pm 18$ vs $51 \pm 17$ years; $P=0.02$ ), were more often men (3:1 vs $1: 1.3$ ratio, $P=0.015)$, and tended to be less often symptomatic at diagnosis $(15 / 29$ vs $38 / 51$; $P=0.08)$. Notably, all bilateral PCs, belonged to the hereditary group.

\section{Characteristics according to the secretory phenotypes}

The vast majority of PCs (73/79) were secreting at diagnosis, although a significant proportion of them $(n=18)$ had no suggestive symptoms. Fifty-two had an adrenergic phenotype, with tumours secreting excess of metanephrine/epinephrine, alone $(n=6)$ or most often in combination with normetanephrine/norepinephrine $(n=46)$, while 21 patients had a noradrenergic phenotype, secreting only normetanephrine/norepinephrine (Table 2).

Table 2 Characteristics of patients at diagnosis (data available for 74 patients), urinary fractionated metanephrines, tumour size and post-surgical outcome in relation to the biochemical profile of their pheochromocytoma $(n=79)$.

\begin{tabular}{l}
\hline \\
\hline Mean age at diagnosis (years) \\
Symptomatic PC at diagnosis \\
Paroxysmal crises at diagnosis \\
Nb of patients with hypertension \\
Systolic blood pressure (mmHg) \\
Diastolic blood pressure (mmHg) \\
Nb of patients with abnormal blood glucose \\
Urinay metanephrine (XULN) \\
Urinary normetanephrine (XULN) \\
Nb of patients with mutation \\
Type of mutation (RET/VHL/SDHXINF1/MAX) \\
Tumour size (cm) \\
Preoperative alpha-blocker treatment ${ }^{\mathrm{b}}$ \\
Haemodynamic complications \\
ICU stay > 1 day \\
Remission \\
Normal blood pressure after Sx \\
Recurrence \\
Malignancy
\end{tabular}

\begin{tabular}{|c|}
\hline $\begin{array}{c}\text { Adrenergic } \\
\text { phenotype }(n=52)\end{array}$ \\
\hline $49.1 \pm 17.3$ \\
\hline $38 / 50$ \\
\hline $32 / 50$ \\
\hline $40 / 50$ \\
\hline $163 \pm 42$ \\
\hline $94 \pm 21$ \\
\hline $32 / 50$ \\
\hline $7.4(1.7-94.1)$ \\
\hline $5.2(0.6-41.2)$ \\
\hline $19 / 45$ \\
\hline $12 / 4 / 1 / 2 / 0$ \\
\hline $5.3 \pm 2.6$ \\
\hline $24 / 52$ \\
\hline $8 / 52$ \\
\hline $9 / 52$ \\
\hline $52 / 52$ \\
\hline $35 / 40$ \\
\hline $1 / 52$ \\
\hline $2 / 52$ \\
\hline
\end{tabular}

\begin{tabular}{c}
\hline $\begin{array}{c}\text { Noradrenergic } \\
\text { phenotype }(n=21)\end{array}$ \\
\hline $40.4 \pm 19.7$ \\
$15 / 19$ \\
$9 / 19$ \\
$16 / 19$ \\
$164 \pm 35$ \\
$91 \pm 18$ \\
$8 / 19$ \\
$0.4(0.2-0.9)^{\mathrm{a}}$ \\
$8.4(2.1-22.0)$ \\
$6 / 19$ \\
$0 / 3 / 2 / 0 / 1$ \\
$6.6 \pm 4.5$ \\
$5 / 21$ \\
$6 / 21$ \\
$7 / 21$ \\
$19 / 21$ \\
$8 / 16^{\mathrm{a}}$ \\
$4 / 21^{\mathrm{a}}$ \\
$5 / 21^{\mathrm{a}}$
\end{tabular}

\begin{tabular}{c}
\hline $\begin{array}{c}\text { Biochemically } \\
\text { silent }(n=6)\end{array}$ \\
\hline $49.0 \pm 20.9$ \\
$0 / 5^{a}$ \\
$0 / 5^{a}$ \\
$0 / 5^{a}$ \\
$126 \pm 12$ \\
$78 \pm 5$ \\
$1 / 5$ \\
$0.7(0.3-0.9)^{a}$ \\
$0.6(0.5-0.8)^{a}$ \\
$4 / 5$ \\
$1 / 3 / 0 / 0 / 0$ \\
$1.7 \pm 0.8^{a}$ \\
$0 / 6$ \\
$1 / 6$ \\
$1 / 6$ \\
$6 / 6$ \\
$6 / 6$ \\
$0 / 6$ \\
$0 / 6$
\end{tabular}

\begin{tabular}{r} 
P-value \\
\hline 0.18 \\
0.01 \\
0.03 \\
$<0.01$ \\
0.09 \\
0.19 \\
0.17 \\
$<0.01$ \\
0.04 \\
0.21 \\
0.02 \\
$<0.01$ \\
0.03 \\
0.42 \\
0.30 \\
0.06 \\
$<0.01$ \\
0.01 \\
0.02
\end{tabular}

Data are shown as mean \pm S.D., medians and (P5-P95) intervals or proportions.

asubgroups with values significantly different from other subgroups without an asterisk; ${ }^{b}$ refers to patients with alpha-blocker treatment for at least 14 days before adrenalectomy.

$\mathrm{Nb}$, number; PC, pheochromocytoma; Sx, surgery; ULN, upper limit of normal range. The $P$ value is derived from one-way ANOVA comparing the three subgroups.

https://ec.bioscientifica.com

https://doi.org/10.1530/EC-20-0537 (c) 2021 The authors Published by Bioscientifica Ltd

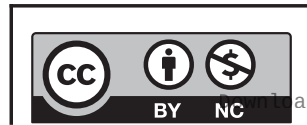

This work is licensed under a Creative Commons Attribution-NonCommercial 4.0 International License. ded from Bioscientifica.com at 04/26/2023 11:28:28AM via free access 
Biochemically silent PCs were found in six patients, all being asymptomatic and normotensive. When comparing adrenergic and noradrenergic tumours, most features at diagnosis were not significantly different between the two subgroups (Table 2). The prevalence of hereditary forms was not different between the adrenergic and noradrenergic groups, but was higher in the biochemically silent patients, reflecting early diagnosis by genetic screening in this group. Interestingly, tumour size differed according to the secretory PC phenotype. Biochemically silent tumours were the smallest ones, while noradrenergic PC were the largest $(P<0.01)$. Furthermore, considering the whole cohort of patients, tumour size significantly correlated with 24 h-urinary metanephrine or normetanephrine excretion (Fig. 1A and B).
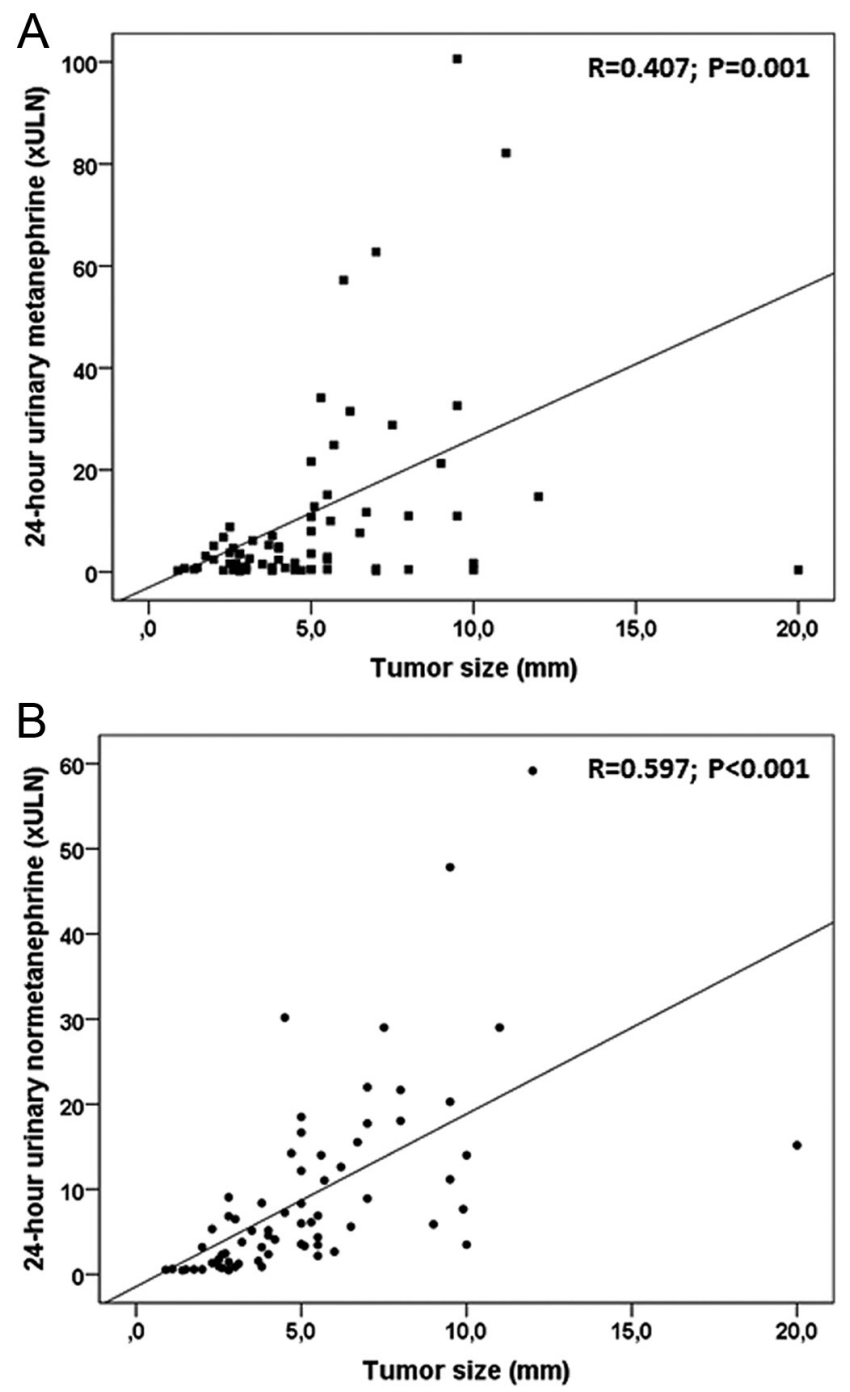

Figure 1

Correlations observed between tumour size and 24-h urinary metanephrine (A) and normetanephrine excretion (B).

\section{Preoperative medical treatment}

Prolonged ( $\geq 14$ days) preoperative alpha-adrenergic receptor blocker treatment had been given in 29 of the 80 patients, never in patients with a biochemically silent PC and less often in patients with a noradrenergic phenotype $(P=0.03$; Table 2$)$. Interestingly enough, alpha-blockade was much more frequently administered to the patients operated during the more recent period 2013-2018 $(20 / 32)$ than in those with surgery performed during the period 1988-2012 $(9 / 58 ; P<0.01)$. Most patients $(n=27)$ were treated with prazosin at a median steady-state dose of $1.5 \mathrm{mg} /$ day (range, $1-7 \mathrm{mg} /$ day). The median duration of alpha-adrenergic receptor blocker treatment in these patients was 30 days (range, 14-90). Additional betaadrenergic blockade was provided to 23 patients after a median interval of 5 days (2-12 days) while 15 other patients were already treated with beta-blockers since several months or years.

When comparing patients with and without preoperative alpha-blocker treatment (Table 3), there was no difference in age, prevalence of hypertension or tumour size between the two subgroups, but a higher proportion of patients with alpha-blockade were symptomatic at diagnosis or had paroxysmal attacks $(P=0.01)$. In addition, these patients had two-fold higher urinary metanephrine levels, although the difference did not reach statistical significance. Regarding surgical outcome, peri-operative haemodynamic complications occurred more frequently in patients without medical preparation $(12 / 51$ vs $3 / 29$, $P=0.05$ ) while these patients had also undergone more frequently laparotomy than patients with preoperative blockade. The number of patients hospitalised in ICU for more than one day tended to be higher in patients without preoperative alpha-blockers (Table 3).

\section{Surgical outcome}

All our patients underwent surgical adrenalectomy, 49 patients by a laparoscopic approach and 31 patients by open laparotomy. The mean time delay between diagnosis and surgery was $56 \pm 46$ days. There was no perioperative death but 15 patients (one-fifth) had severe haemodynamic complications during or within $24 \mathrm{~h}$ after surgery. These subjects had a more severe and symptomatic hypertension at diagnosis, a 2.7-fold-higher excretion of normetanephrines (but not of metanephrines) and a larger tumour (Table 4). They had also undergone more frequently a laparotomy than a laparoscopic adrenalectomy and had more frequently a final diagnosis of malignant PC.

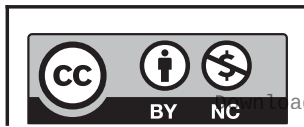

This work is licensed under a Creative Commons Attribution-NonCommercial 4.0 International License. ded from Bioscientifica.com at 04/26/2023 11:28:28AM via free access 
Table 3 Characteristics of patients with PC according to the administration or not of an adequate ( $\geq 14$ days) preoperative alpha-blocker treatment.

\begin{tabular}{lcc}
\hline & $\begin{array}{c}\text { No preoperative alpha-blocker } \\
\text { treatment }(n=51)\end{array}$ \\
\cline { 1 - 2 } Mean age at diagnosis (years) & $44.7 \pm 19.1$ \\
Symptomatic PC at diagnosis & $27 / 50$ \\
Paroxysmal crises & $20 / 50$ \\
Nb of patients with hypertension & $35 / 50$ \\
Systolic blood pressure (mmHg) & $155 \pm 34$ \\
Diastolic blood pressure (mmHg) & $89 \pm 19$ \\
Urinary metanephrine (xULN) & $2.4(0.2-34.0)$ \\
Urinary normetanephrine (xULN) & $5.3(0.5-29.0)$ \\
Tumour size (cm) & $5.3 \pm 3.9$ \\
Nb of patients with laparotomy & $24 / 51$ \\
Nb of patients with haemodynamic & $12 / 51$ \\
complications & $14 / 51$ \\
Nb of patients with ICU stay > 24h &
\end{tabular}

\begin{tabular}{c}
$\begin{array}{c}\text { Preoperative alpha-blocker treatment } \\
(n=29)\end{array}$ \\
\hline $51.1 \pm 16.5$ \\
$25 / 29$ \\
$21 / 29$ \\
$23 / 29$ \\
$170 \pm 48$ \\
$96 \pm 23$ \\
$5.7(0.3-110.0)$ \\
$5.4(0.7-39.9)$ \\
$5.4 \pm 2.3$ \\
$7 / 29$ \\
$3 / 29$ \\
$4 / 29$
\end{tabular}

$\begin{array}{r}\hline \text { P value } \\ \hline 0.14 \\ <0.01 \\ 0.01 \\ 0.37 \\ 0.11 \\ 0.14 \\ 0.06 \\ 0.98 \\ 0.94 \\ 0.04 \\ 0.05 \\ 0.13 \\ \hline\end{array}$

Data are shown as mean \pm S.D., medians and (P5-P95) intervals or proportions.

ICU, intensive care unit; $\mathrm{Nb}$, number; PC, pheochromocytoma; ULN, upper limit of normal range.

In contrast, age, BMI, glucose metabolism and the secretory phenotype (Table 2), as well as the presence and type of a genetic mutation, were not associated with the incidence of haemodynamic complications. Interestingly, while the proportion of patients with alpha-blocker preparation was not significantly different between the two subgroups, patients with severe complications had been treated for a much shorter period before surgery (median of 18 vs 30 days, $P=0.017$ ).
As expected, the mean duration of ICU stay and total duration of surgical stay were longer in the complicated group (Table 4). We also performed a multivariate analysis, which showed that tumour size was the main preoperative factor independently predicting the risk of haemodynamic complications, while a shorter duration of preoperative alpha-blocker treatment was also a significant risk factor when tumour size was not considered (Table 5).

Table 4 Characteristics of patients with PC according to the occurrence or not of severe haemodynamic complications during or within $24 \mathrm{~h}$ after surgery.

\begin{tabular}{lcc}
\hline & & $\begin{array}{c}\text { No haemodynamic complications } \\
(n=65)\end{array}$ \\
\cline { 1 - 2 } Mean age at diagnosis (years) & $47.4 \pm 18.7$ \\
Mean BMI (kg/m²) & $24.5 \pm 4.8$ \\
Symptomatic PC at diagnosis & $40 / 64$ \\
Mean systolic blood pressure (mmHg) & $156 \pm 37$ \\
Mean diastolic blood pressure (mmHg) & $89 \pm 17$ \\
Abnormal blood glucose level at diagnosis & $33 / 64$ \\
Urinary metanephrine (xULN) & $0.9(0.1-16.4)$ \\
Urinary normetanephrine (XULN) & $2.7(0.3-17.5)$ \\
Mean tumour size (cm) & $4.9 \pm 2.8$ \\
Malignant PC (\%) & $3 / 65$ \\
Nb of patients with preoperative & $26 / 65$ \\
alpha-blocker treatment & \\
Duration of alpha-blocker treatment (days) & & $30(13-90)$ \\
Nb of patients with laparotomy (\%) & $17(26 \%)$ \\
Mean ICU stay (days) & $1(0-5)$ \\
Mean surgical stay (days) & $6(4-12)$ \\
\hline
\end{tabular}

\begin{tabular}{|c|c|}
\hline $\begin{array}{l}\text { Haemodynamic complications } \\
\qquad(n=15)\end{array}$ & $P$ value \\
\hline $45.3 \pm 17.4$ & 0.69 \\
\hline $26.1 \pm 5.9$ & 0.30 \\
\hline $13 / 15$ & 0.06 \\
\hline $180 \pm 48$ & 0.04 \\
\hline $102 \pm 29$ & 0.02 \\
\hline $10 / 15$ & 0.29 \\
\hline $0.4(0.1-18.4)$ & 0.54 \\
\hline $7.3(0.3-26.2)$ & 0.05 \\
\hline $7.5 \pm 4.8$ & 0.04 \\
\hline $4 / 15$ & 0.01 \\
\hline $3 / 15$ & 0.15 \\
\hline $18(4-26)$ & 0.02 \\
\hline $14(93 \%)$ & $<0.01$ \\
\hline $3(1-7)$ & 0.01 \\
\hline $12(8-16)$ & $<0.01$ \\
\hline
\end{tabular}

Data are shown as mean \pm S.D., medians and (P5-P95) intervals or proportions.

aRefers to the 29 patients with alpha-blocker treatment for at least 14 days before adrenalectomy; ${ }^{b}$ refers to all 31 patients receiving preoperative alpha-blocker treatment.

ICU, intensive care unit; Nb, number; PC, pheochromocytoma; ULN, upper limit of normal range.

https://ec.bioscientifica.com https://doi.org/10.1530/EC-20-0537 (c) 2021 The authors Published by Bioscientifica Ltd

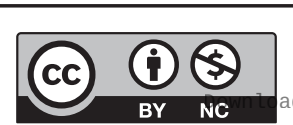

This work is licensed under a Creative Commons Attribution-NonCommercial 4.0 International License. ded from Bioscientifica.com at $04 / 26 / 2023$ 11:28:28AM 
Table 5 Predictive factors for haemodynamic complications during or early after adrenal surgery for a pheochromocytoma according to univariate and multivariate analysis.

\begin{tabular}{|c|c|c|c|c|c|c|}
\hline \multirow[b]{2}{*}{ Variables } & \multicolumn{3}{|c|}{ Univariate analysis } & \multicolumn{3}{|c|}{ Multivariate analysis ${ }^{a}$} \\
\hline & Odds ratio & IC 95\% & $P$ value & Odds ratio & IC 95\% & $P$ value \\
\hline Age at surgery (years) & 0.994 & $(0.964-1.024)$ & 0.690 & - & - & - \\
\hline Symptoms at diagnosis & 4.065 & $(0.845-9.607)$ & 0.180 & - & - & - \\
\hline Urinary normetanephrines (xULN) & 1.048 & $(0.996-1.102)$ & 0.069 & 0.999 & $(0.869-1.149)$ & 0.991 \\
\hline Tumour size $(\mathrm{cm})$ & 1.230 & $(1.040-1.056)$ & 0.016 & 2.074 & $(1.027-4.180)$ & 0.042 \\
\hline $\begin{array}{l}\text { Adequate preoperative alpha- } \\
\text { blocker }\end{array}$ & 0.357 & $(0.096-1.490)$ & 0.157 & - & - & - \\
\hline $\begin{array}{l}\text { Duration of alpha-blocker } \\
\text { treatment (days) }\end{array}$ & 0.861 & $(0.753-0.985)$ & 0.030 & 0.858 & $(0.697-1.052)$ & 0.141 \\
\hline Laparotomy & 39.53 & $(4.83-323.72)$ & $<0.001$ & - & - & - \\
\hline
\end{tabular}

a Only variables which were significant at $P<0.010$ in univariate analysis were introduced in the multivariate analysis. Laparotomy was intentionally not included as this factor outweighed by far all other variables and was highly correlated with both tumour size $(r=0.488 ; P<0.001)$ and urinary normetanephrine excretion $(r=0.430 ; P<0.001)$. When tumour size was removed from the analysis, only duration of preoperative alpha-blocker treatment remained significant with an odds ratio of 0.858 per day of treatment $(0.747-0.987)(P=0.032)$.

\section{Long-term follow-up}

The patients were followed for a median period of 53 months (6-248 months). All patients except the two with metastases were in remission after surgery (78/80). Patients with a noradrenergic PC showed less often normalisation of their blood pressure after surgery as opposed to patients with an adrenergic phenotype $(P<0.05$; Table 2$)$. A relapse of the tumour was observed in five cases, after a median delay of more than 10 years. During follow-up, liver, bone and/or peritoneal metastases developed in five patients so that a malignant PC was finally identified in a total of seven patients of the cohort. The relapsing and malignant PCs had usually a noradrenergic phenotype and were never diagnosed as a biochemically silent tumour (Table 2). The proportions of patients in remission, with relapse, or with a malignant PC were not different between hereditary and sporadic cases (data not shown). At the end of the follow-up, five patients had died, but only two deaths could be attributed to complications of a metastatic pheochromocytoma.

\section{Discussion}

In this study, we report the characteristics of a monocentric cohort of 80 patients with an adrenal pheochromocytoma. These characteristics are consistent with the features usually observed in large series of PCs in the literature $(5,8,18,20,22,23,24)$. In particular, we found no sex predominance, a mean age at diagnosis of 47 years and a mean tumour size of more than 50 $\mathrm{mm}$. However, in contrast to recently reported series (7, 8), the diagnosis in our cohort was still mostly driven by the presence of symptoms or complications typical of a pheochromocytoma. In addition, in agreement with previous publications $(18,22,23,24)$, three-quarters of our subjects had a history of hypertension and more than half had diabetes or impaired fasting glucose level at diagnosis.

In the remaining 21 patients, the tumour was found either as the result of mutation-based case detection testing or following identification of an adrenal incidentaloma on imaging. This mode of presentation has become increasingly prevalent over the last years, due to frequent routine use of abdominal imaging leading to the diagnosis of less active and less symptomatic tumours in older individuals $(7,8)$. It is worth mentioning that $\mathrm{PC}$ is a frequent finding in the work-up of an incidentally discovered mass, accounting for $17 \%$ of them in a recent study (6). The differences in the mode of presentation of PC between our study and more recent series may be explained by the extended period of inclusion and by recruitment bias, as severe and symptomatic tumours were more often referred to our centre.

Case detection testing for patients with genetic predisposition has also become a common way of diagnosing PC, as it was the case for more than half of the asymptomatic patients in our cohort. In total, we found a pathogenic germline mutation in one-third of all index patients, a proportion similar to those reported by previous genetic studies on PPGL, ranging from 25 to $40 \%$ of patients $(2,9,10,11)$. As expected, familial cases were diagnosed at a younger age, had frequently bilateral tumours (25), and, as reported in other studies, were not different compared to sporadic PC in terms of surgical complications $(18,26)$.

Amongst the 73 patients with secreting PC at diagnosis, more than $2 / 3$ were oversecreting epinephrine, most often together with norepinephrine, and less than

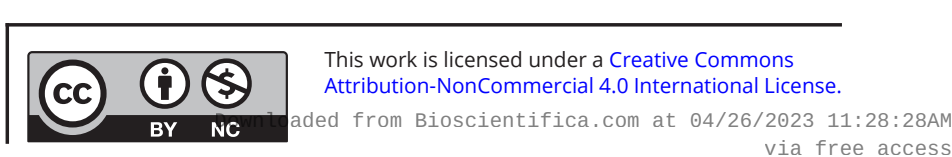


$1 / 3$ had a noradrenergic tumour. This is consistent with previous findings on PC secretory phenotypes based on plasma metanephrines $(19,20,21,27)$. We also observed a significant correlation between tumour size and the amount of urinary normetanephrine and metanephrine excretion. This suggests that as much as plasma metanephrines, 24-h urinary metabolites reflect well tumour activity and secretory phenotype. Moreover, noradrenergic PCs were the largest ones, as shown in other studies $(19,28)$.

We also observed that the noradrenergic tumours showed less often normalisation of blood pressure after surgery compared to the adrenergic phenotype. This is well in line with the recent observation that patients with a noradrenergic PC have more severely impaired diurnal blood pressure variability, permanent damage to the arterial vessels and persistent hypertension (19). In contrast, patients with significantly elevated levels of epinephrine often have paroxysmal hypertension and orthostatic hypotension (29).

It is interesting to note that in 6 cases we found a biochemically silent PC. All these patients were clinically asymptomatic and showed neither paroxysmal attacks nor hypertension at diagnosis. However, even though their clinical presentation was mild, one patient showed perioperative haemodynamic complications, because of catecholamine surges induced by mobilisation and surgical excision of the tumour. Such incidentally discovered normotensive pheochromocytomas with normal metanephrines values have indeed been reported previously and may show haemodynamic instability at surgical excision $(8,30)$.

Surgery is the primary treatment for patients with PCs but still carries a high risk of haemodynamic complications during the perioperative period $(12,13)$. Current guidelines support the use of alpha-adrenergic receptor blockers for at least 10 to 14 days prior to surgery to minimise perioperative complications $(2,14,17,31)$. This recommendation is mainly based on retrospective studies and there is no randomised controlled study that has definitively confirmed the benefits of preoperative medical preparation $(12,14,15)$. Data are even weaker regarding the duration of such medical treatment.

In our study, only $36 \%$ of the patients were treated for at least 14 days with alpha-adrenergic receptor blockers. There was however a significant trend to use more frequently preoperative alpha-blockade over the last years. The treated patients were also more symptomatic at diagnosis and had more frequently paroxysmal attacks. Their pre-treatment systolic and diastolic blood pressure also tended to be higher than in those without medical preparation. Despite this selection bias and a more severe clinical presentation at diagnosis, haemodynamic complications during surgery were less frequent in patients who had received preoperative alpha-adrenergic blocker treatment. Notably also, in the few patients who developed haemodynamic complications despite having received preoperative alpha-blockers, the median duration of treatment was shorter than in those without complications. These observations support the use of preoperative alpha-blocker treatment for a sufficient period of time before PPGL surgery and this recommendation might even be extended to the normotensive patients.

Perioperative complications resulting from severe haemodynamic instability occurred more frequently in patients with a symptomatic PC, higher levels of normetanephrine, a larger or malignant tumour, and a need for open laparotomy. Similar results were found in the study reported by Bruynzeel et al. (26). However, in the latter, there was no difference between those who underwent open surgery and laparoscopic surgery. Our results may be biased by the fact that a laparotomy was usually preferred in the more complex patients. Nevertheless, other studies have also reported that laparotomy was associated with more surgical complications $(32,33)$.

During follow-up, we observed a recurrence in 5 patients, a recurrence rate close to the rate of 0.98 events/100 person-years reported by Amar et al. (34). The proportion of malignant PCs was close to the $10 \%$ figure found in the literature (35). As reported previously $(20,34)$, recurrence and malignancy were associated with initial tumour size, but also with a noradrenergic phenotype which seems therefore to confer a worse prognosis to the tumour.

Our study has several limitations. Due to its retrospective design, some data at diagnosis were missing for a few patients. In addition, this study was carried out in a monocentric cohort and the number of patients may have been insufficient to reach statistical significance for some comparisons. The inclusion period spanned three decades and recommended practice evolved over that time period. Plasma metanephrines were measured only in a minority of patients and, in contrast to the pivotal study by Eisenhofer et al. (20), we rather used 24-h urinary factionated metanephrines to determine the secretory phenotype. We believe however that this approach has also been strongly validated to evaluate tumoural catecholamine secretion (2). The strengths of this study are that all patients were diagnosed and managed by 
the same multidisciplinary team and followed for a long period. It therefore provides valuable results on the reallife management of adrenal PCs in a tertiary center.

In conclusion, we show in this monocentric series of patients with an adrenal pheochromocytoma that the secretory phenotype does not significantly influence the rate of haemodynamic complications during surgery but may affect long-term post-surgical outcome. While biochemically silent PCs are usually of small size and good prognosis, noradrenergic tumours show a worse post-surgical outcome than adrenergic ones, with persistent hypertension despite remission and a higher rate of recurrence or malignant behaviour. Our data also add support to the current recommendation of a prolonged alpha-adrenergic blocker preoperative preparation in patients with PPGL, even in those with normal blood pressure.

\section{Declaration of interest}

The authors declare that there is no conflict of interest that could be perceived as prejudicing the impartiality of the research reported.

\section{Funding}

This research did not receive any specific grant from any funding agency in the public, commercial or not-for-profit sector.

\section{References}

1 Lenders JW, Eisenhofer G, Mannelli M \& Pacak K. Phaeochromocytoma. Lancet 2005366 665-675. (https://doi. org/10.1016/S0140-6736(05)67139-5)

2 Lenders JW, Duh QY, Eisenhofer G, Gimenez-Roqueplo AP, Grebe SK, Murad MH, Naruse M, Pacak K, Young Jr WF \& Endocrine Society. Pheochromocytoma and paraganglioma: an Endocrine Society clinical practice guideline. Journal of Clinical Endocrinology and Metabolism 2014 99 1915-1942. (https://doi.org/10.1210/jc.2014-1498)

3 Nölting S, Ullrich M, Pietzsch J, Ziegler CG, Eisenhofer G, Grossman A \& Pacak K. Current management of pheochromocytoma/paraganglioma: a guide for the practicing clinician in the era of precision medicine. Cancers 201911 1505-1531. (https://doi.org/10.3390/cancers11101505)

4 Santos Jenn RU, Brofferio A, Viana B \& Pacak K. Catecholamineinduced cardiomyopathy in pheochromocytoma: how to manage a rare complication in a rare disease? Hormone and Metabolic Research 201951 458-469. (https://doi.org/10.1055/a-0669-9556)

5 Geroula A, Deutschbein T, Langton K, Masjkur J, Pamporaki C, Peitzsch M, Fliedner S, Timmers HJLM, Bornstein SR, Beuschlein F, et al. Pheochromocytoma and paraganglioma: clinical feature-based disease probability in relation to catecholamine biochemistry and reason for disease suspicion. European Journal of Endocrinology 2019 181 409-420. (https://doi.org/10.1530/EJE-19-0159)

6 Ye YL, Yuan XX, Chen MK, Dai YP, Qin ZK \& Zheng FF. Management of adrenal incidentaloma: the role of adrenalectomy may be underestimated. BMC Surgery 201616 41. (https://doi.org/10.1186/ s12893-016-0154-1)
7 Falhammar H, Kjellman M \& Calissendorff J. Initial clinical presentation and spectrum of pheochromocytoma: a study of 94 cases from a single center. Endocrine Connections 20187 186-192. (https://doi.org/10.1530/EC-17-0321)

8 Gruber LM, Hartman RP, Thompson GB, McKenzie TJ, Lyden ML, Dy BM, Young WF \& Bancos I. Pheochromocytoma characteristics and behavior differ depending on method of discovery. Journal of Clinical Endocrinology and Metabolism 2019104 1386-1393. (https:// doi.org/10.1210/jc.2018-01707)

9 Gimenez-Roqueplo AP, Dahia PL \& Robledo M. An update on the genetics of paraganglioma, pheochromocytoma, and associated hereditary syndromes. Hormone and Metabolic Research 201244 328-333. (https://doi.org/10.1055/s-0031-1301302)

10 Fishbein L, Merrill S, Fraker DL, Cohen DL \& Nathanson KL. Inherited mutations in pheochromocytoma and paraganglioma: why all patients should be offered genetic testing. Annals of Surgical Oncology 201320 1444-1450. (https://doi.org/10.1245/s10434-013-2942-5)

11 Buffet A, Burnichon N, Favier J \& Gimenez-Roqueplo AP. An overview of 20 years of genetic studies in pheochromocytoma and paraganglioma. Best Practice and Research in Clinical Endocrinology and Metabolism 202034 1014-1016. (https://doi.org/10.1016/ j.beem.2020.101416)

12 Challis BG, Casey RT, Simpson HL \& Gurnell M. Is there an optimal preoperative management strategy for phaeochromocytoma/ paraganglioma? Clinical Endocrinology 201786 163-167. (https://doi. org/10.1111/cen.13252)

13 Groeben H, Walz MK, Nottebaum BJ, Alesina PF, Greenwald A, Schumann R, Hollmann MW, Schwarte L, Behrends M, Rossel T, et al. International multicentre review of perioperative management and outcome for catecholamine-producing tumours. British Journal of Surgery 2020107 e170-e178. (https://doi.org/10.1002/bjs.11378)

14 Berends AMA, Kerstens MN, Lenders JWM \& Timmers HJLM. Approach to the patient: perioperative management of the patient with pheochromocytoma or sympathetic paraganglioma. Journal of Clinical Endocrinology and Metabolism 2020105 3088-3102. (https:// doi.org/10.1210/clinem/dgaa441)

15 Schimmack S, Kaiser J, Probst P, Kalkum E, Diener MK \& Strobel O. Meta-analysis of $\alpha$-blockade versus no blockade before adrenalectomy for phaeochromocytoma. British Journal of Surgery $2020 \mathbf{1 0 7}$ e102-e108. (https://doi.org/10.1002/bjs.11348)

16 Lentschener C, Gaujoux S, Thillois JM, Duboc D, Bertherat J, Ozier Y \& Dousset B. Increased arterial pressure is not predictive of haemodynamic instability in patients undergoing adrenalectomy for phaeochromocytoma. Acta Anaesthesiologica Scandinavica 200953 522-527. (https://doi.org/10.1111/j.1399-6576.2008.01894.x)

17 Isaacs M \& Lee P. Preoperative alpha-blockade in phaeochromocytoma and paraganglioma: is it always necessary? Clinical Endocrinology 2017 86 309-314. (https://doi.org/10.1111/cen.13284)

18 Plouin PF, Duclos JM, Soppelsa F, Boublil G \& Chatellier G. Factors associated with perioperative morbidity and mortality in patients with pheochromocytoma: analysis of 165 operations at a single center. Journal of Clinical Endocrinology and Metabolism 200186 1480-1486. (https://doi.org/10.1210/jcem.86.4.7392)

19 Petrák O, Rosa J, Holaj R, Štrauch B, Krátká Z, Kvasnička J, Klimová J, Waldauf $\mathrm{P}$, Hamplová B, Markvartová A, et al. Blood pressure profile, catecholamine phenotype, and target organ damage in pheochromocytoma/paraganglioma. Journal of Clinical Endocrinology and Metabolism 2019104 5170-5180. (https://doi.org/10.1210/ jc.2018-02644)

20 Eisenhofer G, Lenders JW, Goldstein DS, Mannelli M, Csako G, Walther MM, Brouwers FM \& Pacak K. Pheochromocytoma catecholamine phenotypes and prediction of tumour size and location by use of plasma free metanephrines. Clinical Chemistry 200551 735-744. (https://doi.org/10.1373/clinchem.2004.045484)

21 Eisenhofer G, Timmers HJ, Lenders JW, Bornstein SR, Tiebel O, Mannelli M, King KS, Vocke CD, Linehan WM, Bratslavsky G,

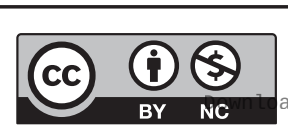

This work is licensed under a Creative Commons Attribution-NonCommercial 4.0 International License. ded from Bioscientifica.com at 04/26/2023 11:28:28AM 
et al. Age at diagnosis of pheochromocytoma differs according to catecholamine phenotype and tumour location. Journal of Clinical Endocrinology and Metabolism 201196 375-384. (https://doi. org/10.1210/jc.2010-1588)

22 Kebebew E \& Duh QY. Benign and malignant pheochromocytoma: diagnosis, treatment, and follow-up. Surgical Oncology Clinics of North America 19987 765-789. (https://doi.org/10.1016/S10553207(18)30244-8)

23 Amar L, Servais A, Gimenez-Roqueplo AP, Zinzindohoue F, Chatellier G \& Plouin PF. Year of diagnosis, features at presentation, and risk of recurrence in patients with pheochromocytoma or secreting paraganglioma. Journal of Clinical Endocrinology and Metabolism 200590 2110-2116. (https://doi.org/10.1210/ jc.2004-1398)

24 Guerrero MA, Schreinemakers JM, Vriens MR, Suh I, Hwang J, Shen WT, Gosnell J, Clark OH \& Duh QY. Clinical spectrum of pheochromocytoma. Journal of the American College of Surgeons 2009 209 727-732. (https://doi.org/10.1016/j.jamcollsurg.2009.09.022)

25 Kittah NE, Gruber LM, Bancos I, Hamidi O, Tamhane S, IñiguezAriza N, Babovic-Vuksanovic D, Thompson GB, Lteif A, Young WF et al. Bilateral pheochromocytoma: clinical characteristics, treatmen and longitudinal follow-up. Clinical Endocrinology 202093 288-295. (https://doi.org/10.1111/cen.14222)

26 Bruynzeel H, Feelders RA, Groenland TH, van den Meiracker AH, van Eijck CH, Lange JF, de Herder WW \& Kazemier G. Risk factors for hemodynamic instability during surgery for pheochromocytoma. Journal of Clinical Endocrinology and Metabolism 201095 678-685. (https://doi.org/10.1210/jc.2009-1051)

27 Petrák O, Klímová J, Mráz M, Haluzíková D, Doležalová RP, Kratochvílová H, Lacinová Z, Novák K, Michalsky D, Waldauf P, et al. Pheochromocytoma with adrenergic biochemical phenotype shows decreased GLP-1 secretion and impaired glucose tolerance. Journal of Clinical Endocrinology and Metabolism 2020105 1878-1887. (https:// doi.org/10.1210/clinem/dgaa154)

28 Funahashi H, Imai T, Tanaka Y, Tobinaga J, Wada M, Matsuyama T, Tsukamura K, Yamada F, Takagi H \& Narita T. Discrepancy between
PNMT presence and relative lack of adrenaline production in extraadrenal pheochromocytoma. Journal of Surgical Oncology 199457 196-200. (https://doi.org/10.1002/jso.2930570312)

29 Zuber SM, Kantorovich V \& Pacak K. Hypertension in pheochromocytoma: characteristics and treatment. Endocrinology and Metabolism Clinics of North America 201140 295-311, vii. (https:// doi.org/10.1016/j.ecl.2011.02.002)

30 Lafont M, Fagour C, Haissaguerre M, Darancette G, Wagner T, Corcuff JB \& Tabarin A. Per-operative hemodynamic instability in normotensive patients with incidentally discovered pheochromocytomas. Journal of Clinical Endocrinology and Metabolism 2015100 417-421. (https://doi.org/10.1210/jc.2014-2998)

31 Pacak K. Preoperative management of the pheochromocytoma patient. Journal of Clinical Endocrinology and Metabolism 200792 4069-4079. (https://doi.org/10.1210/jc.2007-1720)

32 Janetschek G, Finkenstedt G, Gasser R, Waibel UG, Peschel R, Bartsch G \& Neumann HP. Laparoscopic surgery for pheochromocytoma: adrenalectomy, partial resection, excision of paragangliomas. Journal of Urology 1998160 330-334. (https://doi. org/10.1016/s0022-5347(01)62886-6)

33 Fernández-Cruz L, Taurá P, Sáenz A, Benarroch G \& Sabater L. Laparoscopic approach to pheochromocytoma: hemodynamic changes and catecholamine secretion. World Journal of Surgery 199620 762-769; discussion 768. (https://doi.org/10.1007/ s002689900116)

34 Amar L, Lussey-Lepoutre C, Lenders JW, Djadi-Prat J, Plouin PF \& Steichen $\mathrm{O}$. Recurrence or new tumours after complete resection of pheochromocytomas and paragangliomas: a systematic review and meta-analysis. European Journal of Endocrinology 2016175 R135-R145. (https://doi.org/10.1530/EJE-16-0189)

35 Pacak K, Eisenhofer G, Ahlman H, Bornstein SR, GimenezRoqueplo AP, Grossman AB, Kimura N, Mannelli M, McNicol AM, Tischler AS, et al. Pheochromocytoma: recommendations for clinical practice from the first International Symposium. Nature Clinical Practice: Endocrinology and Metabolism 20073 92-102. (https://doi. org/10.1038/ncpendmet0396)

Received in final form 10 November 2020

Accepted 14 December 2020

Accepted Manuscript published online 15 December 2020 https://ec.bioscientifica.com https://doi.org/10.1530/EC-20-0537 (c) 2021 The authors Published by Bioscientifica Ltd
This work is licensed under a Creative Commons Attribution-NonCommercial 4.0 International License. ded from Bioscientifica.com at 04/26/2023 11:28:28AM 